University of St. Thomas, Minnesota

UST Research Online

Center for Ethics in Practice Papers and

OCB Centers, Institutes and Other Scholarly

Reports

Initiatives

2013

\title{
Modern risk management through the lens of the ethical organizational culture
}

Douglas Jondle Ph.D.

University of St. Thomas, Minnesota, djjondle@stthomas.edu

T. Dean Maines

University of St. Thomas, Minnesota

Michelle Rovang Burke

University of St. Thomas, Minnesota, rova1061@stthomas.edu

Peter C. Young

University of St. Thomas, Minnesota

Follow this and additional works at: https://ir.stthomas.edu/ocbctrcebc

Part of the Business Administration, Management, and Operations Commons, and the Business Law, Public Responsibility, and Ethics Commons

This Article is brought to you for free and open access by the OCB Centers, Institutes and Other Scholarly Initiatives at UST Research Online. It has been accepted for inclusion in Center for Ethics in Practice Papers and Reports by an authorized administrator of UST Research Online. For more information, please contact asle4660@stthomas.edu. 
Original Article

\title{
Modern risk management through the lens of the ethical organizational culture
}

\author{
Douglas Jondle, T. Dean Maines, Michelle Rovang Burke* \\ and Peter Young \\ University of St. Thomas, Opus College of Business, 1000 LaSalle Avenue, \\ Minneapolis, MN 55403-2005, USA. \\ *Corresponding author.
}

\begin{abstract}
Most recent efforts to create guidance for modern risk management practices emphasize the importance of connecting risk management policy and practice with an organization's culture and values. However, identifying or establishing that connection is not widely discussed or understood. What does it mean to state that risk management is an expression of an organization's values? This article discusses the basis for identifying the connection between organizational values through the lens of the Ethical Organizational Culture and attempts to draw out linkages with current risk management thinking on the subject. The establishment of a basis of identifying organizational values and their link to risk management policy and practice is illustrated through a case analysis of the Veritas Institute's Self-Assessment and Improvement methodology.

Risk Management (2013) 15, 32-49. doi:10.1057/rm.2012.11
\end{abstract}

Keywords: modern risk management; the ethical organizational culture; risk management and culture; risk management; organizational values

While all organizations manage risk to some degree, this International Standard establishes a number of principles that need to be satisfied to make risk management effective. This International Standard recommends that organizations develop, implement and continuously improve a framework whose purpose is to integrate the process for managing risk into the organization's overall governance, strategy and planning, management, reporting processes, policies, values and culture (ISO, ISO 31000, 2009). 


\section{Introduction}

Over the past 10 years, a number of guidelines, frameworks and standards have emerged, all pressing for a more comprehensive approach to risk management. Arguably, one of the more frequently referenced, but seldom examined, aspects of these documents is the assertion that risk management should align with an organization's culture and its values. Although this assertion - perhaps, 'assumption' is a better word - is nowhere fully explained, the implication seems to be that a comprehensive approach to risk management represents a fundamental change in an organization and that organizations will resist such change if it is inconsistent with culture and values.

In a conversational context, the idea that risk management is an expression of an organization's values seems sensible enough, but how is alignment between values and risk management discerned and assured? And if alignment is achieved, does not that suggest that risk management might be subject to quite different interpretations from organization to organization, and from culture to culture (leading to an interesting question: Beyond bare-bones framing, does it even make sense to aspire to a global uniform standard of practice?).

The purpose of this article is to search for a means of linking risk management with organizational values. This article engages this search by first reviewing present thinking regarding organizational values (through the lens of the 'Ethical Organizational Culture' concept); then considering how risk management presently looks at values; and finally evaluating the means through which a firmer connectivity between risk management practices and values may be found, measured and examined. Alongside this discussion, the concept of ethical risks (or risks arising from values) also receives attention.

\section{The Ethical Organizational Culture}

Schein (2004) writes that organizational culture, at its root, is composed of individuals whose learned responses at the fundamental level are derived from an organization's taken-for-granted homologous 'assumptions and beliefs'. Organizational cultures are manifestations of formal and informal systems, processes and interactions, according to Cohen (1993). Formal characteristics integrate into organizational culture through the quality of the organization's leadership and its subsequent ability to manage processes and people, and its overarching business and governance structures, policies, and socialization mechanisms to regulate employee behavior, employee reward systems and decision-making processes. Informal elements of organizational culture, in turn, rely on values, implicit behavioral norms, role models, organizational myths and rituals, organizational beliefs, historical anecdotes, and language (Dion, 1996; Trevino and Nelson, 2004). 


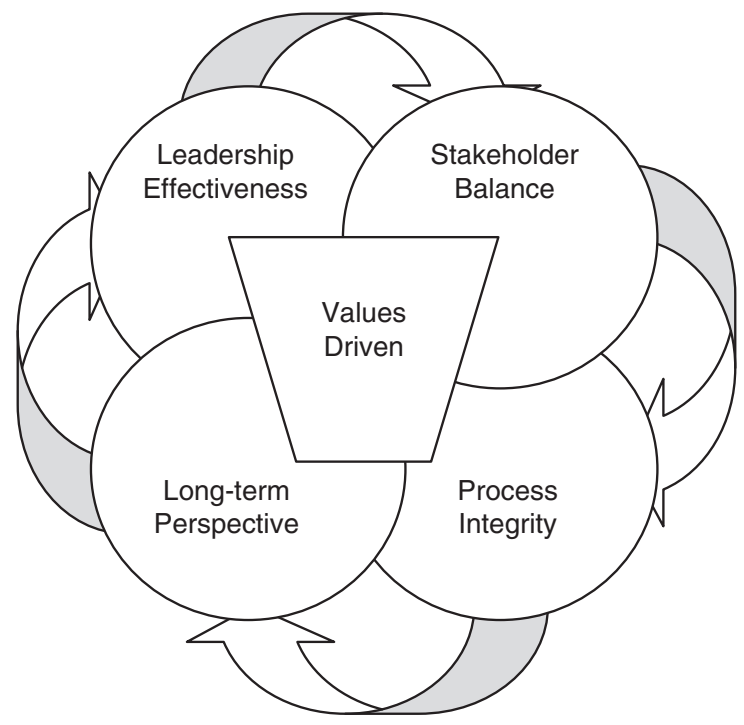

Figure 1: CEBC Model of the five characteristics of an ethical business culture.

Ardichvili and Jondle (2009) note that ethical business culture is based on an alignment between formal structures and processes, and informal recognition of heroes, stories and rituals that inspire organizational members to behave ethically. This includes personal moral development and exhibition of authenticity by leaders. When developing and sustaining ethical culture, organizations must be willing to address not only formal compliance requirements, but focus on the identification of corporate values and the alignment of those values with all other elements of the culture. Ardichvili et al (2009) at the Center for Ethical Business Cultures (CEBC) identified a model of ethical business culture (CEBC Model) consisting of five characteristics: Values-Driven, Leadership Effectiveness, Stakeholder Balance, Process Integrity and Longterm Perspective (Figure 1). In validating the ethical business culture model and ensuing survey instrument, Jondle et al (forthcoming) reported on the results of exploratory and confirmatory factor analysis and convergent validity testing to identify a construct consistent with the five characteristics mentioned above. They hypothesize, much as individuals are uniquely composed from DNA, the ethical cultures of organizations are the resultant expression of specific combinations of organizational values - each organization models a unique ethical culture.

It is no accident that the CEBC Model presents a platform on which corporate conscience is indelibly imprinted. By focusing on the five characteristics of an ethical business culture, organizations have specific directions to take in building and sustaining their organizational culture based on ethical principles and metrics to measure progress. 


\section{The ethical organizational culture model: A closer look}

At the core of the CEBC Model is the Values-Driven characteristic. Values define an organization's character (Freeman et al, 1988; George, 2003), 'not to be compromised for financial gain or short-term expediency' (Collins and Porras, 1994). For an organization, the 'core values' (Carroll and Buchholtz, 2009) not only build the superstructure on which accepted employee behavior is based, but more importantly they functionally and strategically capture and instill a sense of purpose that is transparent and actually 'mean[s] something' towards building organizational consensus (Lencioni, 2002). To put it in the context of the CEBC Model, values define organizational culture; organizational culture defines how its leaders behave, how stakeholders are treated, how internal processes function and the degree to which the organization's perspective is long term.

According to Goodpaster (2007), an ethical culture displays two distinct languages. One is defined by espoused values; the other by values in action. The concept of dual values, formal (espoused, stated) and informal (values in action, practiced) is not new (Schein, 2004). Formal values are those embraced by the organization to influence behavior and so used by the organization to define goals. Examples of stated values can be ascertained through an organization's mission, vision and value statements, and codes of conduct and ethics. Practiced values on the other hand are generally unwritten. They are behavioral in nature, actively practiced within the organization. They are based on the experiences of employees within the organization or stimuli originating outside the organization and can have negative or positive impact on organizational goals.

In corporations with a conscience - those based on ethical cultures alignment, though never perfect, exists between stated and practiced values fostering positive outcomes (Goodpaster, 2007). When there is a misalignment of stated and practiced values, the culture is strained and the second language (practiced values) generally dominates. As the misalignment gap increases, so increases organizational dysfunction and decreases operational effectiveness. In other words, for an organization to be successful, it must manage the dynamic interaction 'between the stated values that characterize desired behavior and the practiced values that moderate and reinforce the actual behavior within the organization's core business functions and processes' (Jondle et al, forthcoming, manuscript p. 17).

Although the Values-Driven component of the model is of central interest to this article, it is worthwhile to briefly map out the other components as they do have relevance to the challenge of linking risk management to cultures and values.

Effective organizations are ones that are managed by effective leaders (Brown and Trevino, 2006). The construct, Leadership Effectiveness, presumes that an 
ethical culture originates with top management and is conveyed by example throughout the organization. By necessity, an organization's values are representative of its leadership's personal behavior in such a manner as to reinforce acceptable behavior for the organization's employees and various stakeholders.

Stakeholder theory draws on the belief that leaders, acting as agents of the organization, shoulder fiscal responsibilities and duties of performance to a diverse group of stakeholders with specific interests in the well-being of the organization (Freeman, 1994). As a result of this stakeholder diversity and competing interests among stakeholders, tension or conflict is an inherent component of the Stakeholder Balance construct. Managing the conflict through stakeholder dialogue becomes the key to successfully balancing stakeholder needs and demands. An additional and important concept within Stakeholder Balance is the act of stakeholder reciprocity. There are expectations of reciprocated behavior upon the corporation by the stakeholder. This community of stakeholders, including the corporation, truly becomes a community with shared values, common goals and shared benefits.

Implementation of organizational policy and the creation of business functions created in concert with the prescribed corporate values describe the characteristic Process Integrity. Process Integrity is the mechanism from which institutionalization of desired behavior throughout the organization is accomplished. It is characterized by linking company values to how business functions and processes (that is, how companies hire, fire, reward, communicate and manage risk) are designed and implemented. It is at the heart of building and sustaining an ethical organization - through its commitment to establish desired and accepted ethical behavioral norms and to align and assess its processes in reinforcing those norms.

What is the organization's purpose (Handy, 2002)? Is its existence dependent upon its ability to 'maximize shareholder value' or is it to provide fair and equitable return to its stakeholders? These questions epitomize the fifth element of an ethical business culture - the Long-term Perspective. An ethical business is one strategically managed for the long term, not for short-term gain as one exemplified by quarterly results at the detriment of long-term survivability and value creation. Leadership's role is defined through its ability to evolve and design strategy that fosters both long-term growth and progressive innovation. An organization focused on the long-term manages all its resources (that is, employees, customers, community, environment) with an eye to the future.

Returning to the core characteristic of the CEBC Model (Values-Driven), what exactly are the values of an Ethical Organizational Culture? It is proposed here that ethical cultures are quite different in terms of the exact array of values espoused by an organization, and that it would be - perhaps - more useful to understand how organizational values can be identified and assessed, 
especially with reference to their connections to risk management. In other words, the best use of time may not be in searching for a universally acceptable set of values, but determining the best way in which values (whatever they are in a particular organization) can be found. Nevertheless, some attention will have to be paid to the matter of the influence of specific values on risk management. One issue warranting separate study (it will be examined briefly later) is the question: Does ISO 31000 imply the acceptance of certain values? This latter question turns out to be important, for if implementation of ISO 31000 means the acceptance of its underlying values, does not that directly contradict the idea that risk management derives from a specific organization's own values and culture?

Perhaps most importantly for this article, the CEBC Model places great emphasis on the distinction between espoused values and values in action, which may give rise to a 'space' within which many ethical risks can be said to originate. As Young (2004) noted, commenting on earlier insights from Goodpaster (1997), the concept of teleopathy (goal sickness) may be a useful starting point for exploring the presence of ethical risks within an organization. Teleopathy posits the view that an organization's Values, Goals and Means stand in precarious balance with one another and that breaks, or distortions, in the links among the three tend to produce ethical issues. However, as CEBC observes, there may be a linkage issue that precedes the Values, Goals and Means connection and that is the link between Espoused Values and Values in Action. Breaks or distortions in that link, arguably, provide a basis for further linkage of difficulties between Values-Goals, Goals-Means and Means-Values. There also exists an overarching link between an organization's espoused values and broader societal values. As Young noted, there may be internal consistency linking goals and means to socially reprehensible values and thus separation between social and organizational values also serve as a source of ethical risks.

The preceding discussion may require an illustration. As noted, within an organization, a source of risk may be found in the space between the values an organization publicly espouses, and the organization's values as seen in its practices. Thus, the question analysts would likely ask is - What do an organization's espoused values translate into with respect to the organization's day-to-day behavior? For example, if trust and transparency are stated values, how do those values translate into actual behavior within the organization and between the organization and its stakeholders? The teleopathy concept would argue that a lack of consistency between espoused and practical values would be an environmental source of ethical risks. A declaration of the importance of trust as an organizational value, when placed alongside behaviors that do not convey (and indeed, may oppose) that value, can provide a basis for ethical risks (some issues may become undiscussable; 'the elephant in the room' phenomenon; behaviors may adjust to create the appearance of value consistency leading to stress on other aspects of organizational behavior). 
External to the organization, a potential further source of ethical risk could be found in link between broader societal values and either the espoused or the practiced values of the organization. Most modern societies place some valuebased constraints on exploitation of children (child labor), and indeed the organization may espouse a similar view ... but its values in action may permit child exploitation in its global supply chain. Thus, there are two effective venues for the emergence of ethical risks - the difference between internal espoused values and values in action and the difference between broader societal values and the organization's values in action.

\section{Values: The Risk Management Perspective}

An environment of expectations has emerged over the past 15-20 years with respect to the practice of risk management. Evidence can be found in wideranging sources: regulator and rating agency interests in corporate resiliency, internal and external audit requirements, citizen expectations for local government responsiveness to community safety issues; or broader global expectations for meaningful responses to climate change - just to name a few examples.

There are numerous reasons why this has happened. At the widest societal level, writers like Ulrich Beck (1992) have observed that these rising expectations are actually linked to many aspects of modern life: to information systems and the influence of the media; to fears arising from new and highly mysterious (at least mysterious to the general public) risks; to greater degrees of global interconnectivity; and, paradoxically; to the intensifying focus on residual risk as science and technology improve quality of life in wide-ranging ways (for example, controlling infectious diseases, improved public safety). On a slightly smaller scale, many of these expectations also have emerged in response to specific events: sensational cases of corporate fraud and malfeasance, oil spills, volcanoes, terrorism, financial crises (World Economic Forum, 2011).

As noted in the introduction to this article, the sharpened edge of modern expectations is seen in the proliferation of guideline/standards documents focused on risk management (ISO 31000 is a particularly notable current example), and various nation-specific frameworks and standards. Further, as Figure 2 suggests, there are many other direct and indirect ways in which risk management has become an expectation (or even a requirement) in the service of addressing a specific risk issue - financial regulation, trade rules, labor practices.

Taken as a whole, but even when taken individually, the instruments of modern expectations provide a general picture of the type of risk management 'expected'. It is holistic, integrated, comprehensive, policy-driven and systematic. The term Enterprise Risk Management (ERM) is often used in reference to this form of risk management, although in fact ERM is just one version of this idea. While not claiming any special naming rights, the authors introduce 


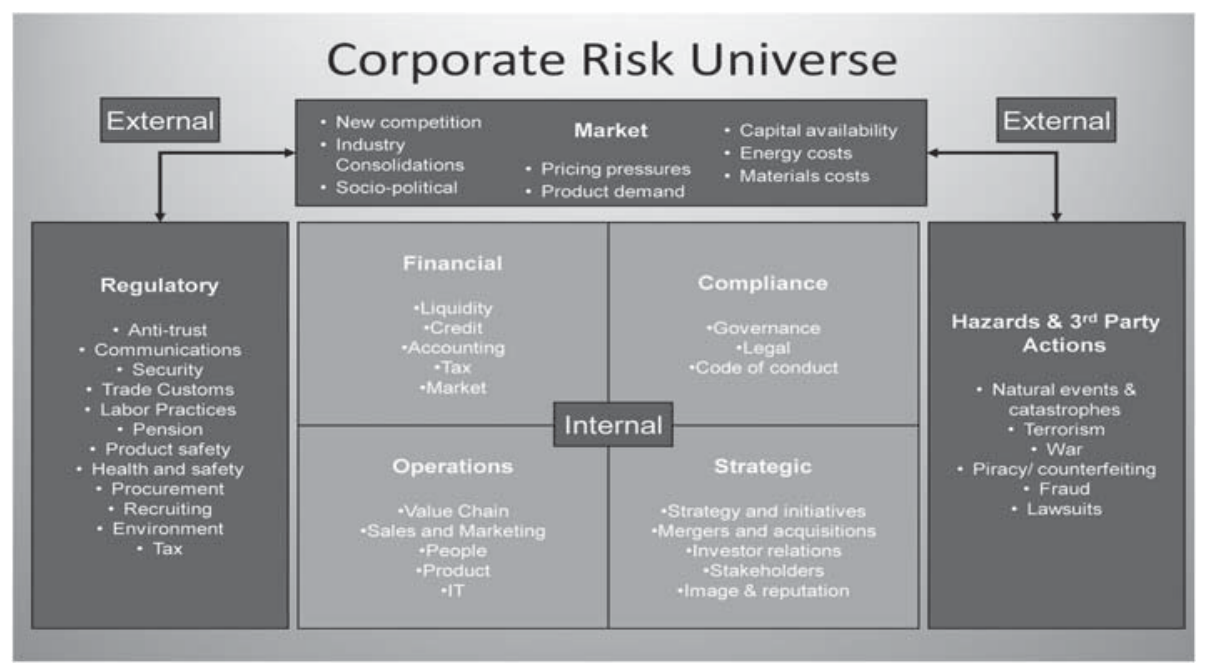

Figure 2: $\quad$ Corporate rise universe.

a slightly relaxed term and will hereafter refer to this phenomenon as Modern Risk Management (MRM).

MRM is reasonably well framed and - at least among specialists in the field - fairly well understood (though there are many remaining or new issues; for example, see Smith and Fischbacher, 2009). Broadly, organizations are expected to devote attention to developing an approach to risk management that is attuned to the environmental conditions and the context of an organization's current situation. This is variously expected to include (i) an understanding of the history (of the organization or situation), (ii) an evaluation of the external and internal environments, including, (iii) some form of stakeholder assessment and (iv) an evaluation of the organization's goals, purposes and intentions. Once the context has been established, MRM involves risk assessment, response to/treatment of risks, evaluation and monitoring, and effective communication to stakeholders. Figure 3 shows, for example, how ISO 31000 frames the MRM process.

Underlying this framework are several ideas that also are present in most of the current guidelines, standards and frameworks.

- Risk management exists to directly support the fulfillment of organizational (or situational) objectives, and thus is seen as an element of the policy setting, strategy setting, governance dimension of management and leadership (Andersen and Schrøder, 2010, Chapter 1).

- Although top management is the target for some clear expectations, there is a general view that the actual implementation and practice of MRM is something that is dispersed throughout the entire organization and embedded in 


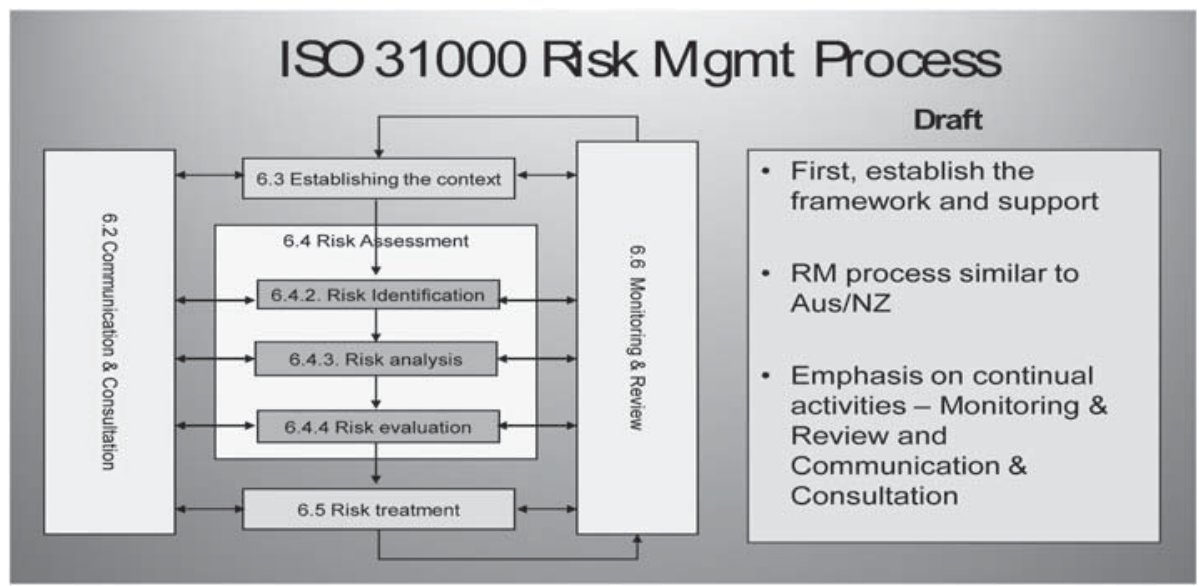

Figure 3: Influences on MRM adoption.

processes and systems. 'All managers are risk managers within the scope of their specific responsibilities' is a phrase often cited in support of this general notion (Schrøder, 2006).

- Risk is seen as producing both positive outcomes (via opportunities) as well as negative outcomes (via hazards). Owing to this ecumenical view of risk, the purposes of risk management broadly are not focused only on eliminating or reducing risk, but on finding a proper balance of risk taking/risk mitigation (Williams et al, 1998, Chapter 2).

In addition, MRM is expected in some way to connect itself to organizational culture and organization values. ISO 31000, the most recent (and perhaps the most ambitious) guidance, references the embedding of risk management in an organization's culture, stating (t)he risk management process should be an integral part of management, embedded in the culture and practices, and tailored to the business processes of the organization (ISO, ISO 31000, 2009).

Following a different line of inquiry, Young (2004) sought to discover whether values actually produce risks, which led to consideration of the concept of 'ethical risks' (revisited in 2009). It remains unclear if ethical risks represent a distinct category of risks or whether they are an aspect of existing categories, but in addition to understanding how risk management reflects organizational values, Young argued it is a useful exercise to think about social, cultural and organizational values also as an environmental source of risk.

Potentially, useful threads emerge in this limited work. First, values and culture seem to produce risks that need to be identified and managed. Second, the relationship of an organization's values to broader societal values can 
also serve as a source of ethical risk. Third, there is no heretofore obvious methodology for organizing an understanding of risks that specifically arise from values (and culture).

\section{Establishing a 'Values' Context for MRM}

The current academic and practitioner work in risk management seems to anticipate an eventual link-up with organizational ethics, but does not present easy and obvious ways for this to happen. Equivalently, the Ethical Organizational Culture concept anticipates an inclusion of risk-related perspectives, but does not offer language necessary to construct a systematic approach to assessing and addressing ethical risks. This presents two specific issues for consideration. First, how is risk management aligned with organizational values? Second, do problems with misalignment of values lead to a category of risk called 'ethical risks'? We could consider the values dimension of the concept of risk. ISO 31000 defines risk as the 'effect of uncertainty on objectives', belying a distinct managerial orientation. Objectives derive from an organization's strategy, mission and vision, and thus the meaning of risk is tied to its impact on the intentions of the organization, which are informed by its values. Not all objectives are exclusively values-driven, but ISO does imply that risk is defined in relation to organizational values.

Adopting a wider perspective, risk is defined as 'variation around expectation', which establishes two ways that risk relates to organizational values (Williams et al, 1998, Chapter 1).

(1) Expectation is determined by objective observation, but also is influenced by cultural filters and the implicit values therein. For example, cultures establish beliefs and values related to 'the other' (that is, those not within the group), and this value establishes expectations as to future behavior of those not within the group. Additionally, even when expectation derives from highly scientific methodologies, the selection of subject for evaluation or the selection of methodologies (do we experiment with animals?), involves values-based choices.

(2) Variation may be mathematically measured, but the meaning of various outcomes is not mathematically determined. What does it mean to a manager to be told that there is a 95 per cent probability a product defect is not likely to injure customers?

Thus, can it be argued that values not only influence the dimensions of risk (expectation and variation) but they - at least indirectly - define the exposure to risk (objectives)? This would suggest that any approach to risk assessment would be well served to include a consideration of the ethical aspects of that risk and, second, that the express values underlying organizational objectives be identified in an ISO-guided risk assessment process. 
Young's (2004 and 2010) work provide some basis for inserting a consideration of ethics into risk assessment, but the second issue 'risk-assessing the values that underlie organizational objectives' is a bit more problematic. How is this done? The following section of this article builds off an existing ethical assessment methodology to offer a suggested path forward.

One final word here on the risk management perspective on value. Is ISO 31000 itself based on express or implicit values? This question challenges risk managers because it could mean that acceptance of the ISO 31000 methodology also requires acceptance of the values on which the statement is based. Certainly, this is intriguing, and perhaps also troubling, as ISO asserts that risk management must be driven by specific organizational culture and values - so what does an organization do if ISO values conflict with organizational culture and values?

As this is, effectively, a sidebar issue for this article, comments can only be provisional. Nevertheless, examination of the ISO 31000 document indicates that the following values arguably are implicit in that version of MRM:

- Respect for the scientific method

- Respect for the past (the importance of remembering)

- Vigilance

- Fairness and respect for all stakeholders

- Personal and corporate responsibility for actions and consequences

- The principle of collaborative effort

- Openness, transparency and honesty

- Long-term time orientation

Other values may be discerned - the list here is only indicative. One could see conflict arising from several of these implied values and the values (espoused or values in action) of a particular organization - or perhaps more likely while ISO values may align with espoused values, they may not align with values in action. This would be an interesting finding from a diagnostic standpoint, but the larger point here is that ISO 31000 is not a value-free document, and difficulties in implementation may come down to the fact that external values are entering the frame as well as recommended practices. Indeed, how could ISO 31000 be value-free?

\section{A Possible Method}

The Veritas Institute has developed a set of assessment and improvement tools that help for-profit and not-for-profit organizations evaluate whether their management systems and cultures support and sustain their espoused values. These tools enable firms to assess the distance or 'gap' between the values they profess and their values in action, and to take corrective action 
to close that gap. Use of the tools also fosters improved clarity about the nature and practical implications of a firm's espoused values. The tools help leaders form an ethical business culture by aiding values deployment and values alignment. That is, they help leaders ensure that their organization is both values-driven and marked by process integrity, that is, the firm's stated values are embedded within the strategies, policies, procedures and practices that shape how it creates goods or delivers services.

The Institute's tools are based on a method known as the Self-Assessment and Improvement Process (SAIP). The SAIP method integrates insights from corporate ethics, spirituality and total quality management. More specifically, its underpinnings include the principle of moral projection, the practice of conscience examination and the organizational self-assessment process used within the Baldrige Performance Excellence Program.

The SAIP method builds on the parallel between the person and the organization by extending to the latter the practice of conscience examination, a discipline employed by individuals for centuries to aid their moral and spiritual development. The SAIP creates an organizational analog to the frameworks - the structured series of questions - that individuals frequently use for this examination. It does this by adapting the approach to the organizational self-assessment that was pioneered by the Baldrige Performance Excellence Program. Following the Baldrige model, the SAIP translates a set of ethical principles into a systematic inventory of questions concerning an organization's management system, that is, the operating policies, processes and practices that shape how it performs its work. By answering the questions within the inventory on the basis of evidence - for example, documentation describing how the organization currently operates, and data indicating the outcomes it has achieved - and then scoring these responses using a set of evaluation guidelines, a firm can determine the degree to which it has integrated vital moral aspirations within its operating policies and procedures. By highlighting strengths and deficiencies, the assessment helps leaders formulate and launch improvement initiatives designed to more comprehensively embed moral principles within their firm's management system (Maines, 2011).

The SAIP method is flexible, and can be used with different sets of ethical principles. Regardless of the specific principles employed, all SAIP-based assessment tools foster an enhanced awareness of the ethical concerns confronting an organization. The questions they pose highlight actual and potential misalignments between what an organization does and what it says, between how it operates and the moral values or principles it professes. They permit an organization to examine its management system critically, with an eye toward discovering whether the decisions and actions that system prompts are congruent with its moral aspirations.

Assessment tools based on the SAIP method arguably place risk management at the service of a firm's moral commitments. By enabling leaders and 
managers to discern how their organization's processes and practices may be in tension with its values, they create the possibility of systematically identifying value-specific risks, and of initiating corrective action to mitigate risks through improved alignment between moral aspirations and action. Furthermore, as these tools are intended to be applied periodically and not simply as a one-time event, they help establish the management of ethical risk as an ongoing discipline within a firm. That is, they foster a risk management mentality in relation to both espoused values (for example, the risks to which specific values may give rise) and inconsistencies between espoused values and values in action (for example, risks arising from misalignments between these two values sets).

\section{An illustration}

One of the Veritas Institute's SAIP-based assessment tools, the Catholic Identity Matrix (CIM), enables Catholic health systems and hospitals to examine themselves from the inside out. That is, the CIM helps a Catholic healthcare institution identify the extent to which values and principles rooted in the Catholic moral tradition have been integrated within its management system, to advance its mission and benefit stakeholders. The forerunner of the CIM was developed in 2006 by Ascension Health, the largest Catholic and not-for-profit health system in the United States. Ascension Health partnered with the Veritas Institute in 2007 to integrate the SAIP method within this prototype, thereby making it more rigorous and evidence-based.

The CIM is grounded in six principles of Catholic moral teaching specific to the ministry of healthcare. The formulation of these principles draws from a number of sources, including the Ethical and Religious Directives for Catholic Health Care Services, the experience of Catholic healthcare leaders and the Catholic social tradition. The principles include solidarity with the poor, holistic care, respect for life, participatory community of work, stewardship and acting in communion with the Church. The CIM evaluates a Catholic healthcare institution in light of each principle and a framework for organizational maturity and development. This framework describes the steps necessary to implement a principle within an organization's management system, namely, through effective planning, aligning leaders through reporting metrics and incentives, operationalization in work processes, training, and the assessment of outputs and impact. Parenthetically, physicians rooted in the Hippocratic tradition find much in the Catholic moral tradition that is congenial with their values and principles. Rather than viewing the Catholic moral tradition as an inhospitable locus for their practice, these individuals tend to find this tradition's values and principles as complementary to their own.

Table 1 illustrates the CIM assessment framework. 
Table 1: Catholic identity matrix framework

\begin{tabular}{|c|c|c|c|c|c|c|}
\hline & Planning & Alignment & Process & Training & Measurement & Impact \\
\hline $\begin{array}{l}\text { Solidarity with those who } \\
\text { live in poverty }\end{array}$ & 1.1 & 1.2 & 1.3 & 1.4 & 1.5 & 1.6 \\
\hline Holistic care & 2.1 & 2.2 & 2.3 & 2.4 & 2.5 & 2.6 \\
\hline Respect for human life & 3.1 & 3.2 & 3.3 & 3.4 & 3.5 & 3.6 \\
\hline $\begin{array}{l}\text { Participatory community of } \\
\text { work and mutual respect }\end{array}$ & 4.1 & 4.2 & 4.3 & 4.4 & 4.5 & 4.6 \\
\hline Stewardship & 5.1 & 5.2 & 5.3 & 5.4 & 5.5 & 5.6 \\
\hline $\begin{array}{l}\text { Act in communion with the } \\
\text { Church } \\
\text { Common good and human }\end{array}$ & 6.1 & 6.2 & 6.3 & 6.4 & 6.5 & 6.6 \\
\hline
\end{tabular}

A CIM application yields a qualitative portrait of the current state of an organization's management system, and a quantitative appraisal of the extent to which the six principles have been embedded within this system. This information allows leaders to identify opportunities for improvement and to formulate initiatives designed to help their organization embody more fully the mission and aspirations of Catholic healthcare. Periodic use of the CIM enables Catholic healthcare organizations to establish a discipline of sustained, ongoing improvement in response to the challenge of mission integration.

The results of a CIM assessment conducted at the system (or corporate) level in 2007 helped Ascension Health to identify strengths and opportunities for growth. The latter included operationally defining and implementing the practice of holistic care; enhancing associate engagement, in part giving employees greater voice in how their work is structured; and improving the process through which system-wide initiatives are placed into practice. Ascension Health responded to the findings by launching improvement efforts aimed at these three opportunities.

In 2009, Ascension Health decided to conduct system-level CIM assessments every 3 years. This interval gives improvement initiatives emerging from a given assessment time to mature before the subsequent CIM application is performed. Ascension Heath's most recent system-level CIM assessment occurred in August 2010. Results from this assessment showed improvement in many areas, as judged against the baseline established by the 2007 CIM application. The 2010 assessment also confirmed the need to continue improvement efforts focused on operationalizing holistic care and more fully developing a participatory community of work. In addition, it highlighted new improvement opportunities. Action plans based in part on the 2010 results focus on developing a strategy for enhanced physician engagement and creating a structure to better support organizational learning (Brinkmann and Johnson, 2011).

This illustration pre-dates the insertion of explicit risk management elements within the assessment. The Veritas Institute is now considering the inclusion of 
questions that directly address such elements. Under current consideration, for example, are:

- Questions concerning uncertainties and risks tied to each element of the matrix ('We expect X to happen (or not happen), but what if we are wrong ... what are the consequences of unexpected or unintended outcomes?' Alternatively: 'What is the risk of mis-framing our analysis of organizational values?');

- Questions addressing possible factors outside the normal managerial range of vision that might influence the organization's ability to live up to its moral values and aspirations;

- Questions concerning risks entailed by a commitment to specific principles within the assessment framework, which otherwise would not exist for the organization. In other words, is adherence to particular values in-and-of-itself a source of risk?

- Questions regarding issues of risk tolerance (How much risk are we willing to tolerate? How much risk are we able to carry? At what point does stress on our values and beliefs actually fracture the connection between espoused values and values in action?).

The CIM has been recognized as a best practice in Catholic health care. To date, it has been applied within six health systems in the United States. Plans for extending the CIM to Catholic hospitals in other countries during 2012 are now emerging. In addition, the Veritas Institute is collaborating with its partners to address the needs of organizations outside of healthcare. The latest SAIP tool is the Business Ethics and Assessment Method. This assessment allows a company to audit its management system and culture through pointed queries based on standards taken from ISO 26000 and - notably - general components of ISO 31000. By using this tool to systematically examine the values reinforced by its management system (including risk management), as well as those present within its culture, a corporation can begin a journey whose destination is not simply effective compliance, but formal processes and a culture that consistently supports and reinforces ethical conduct (United States Sentencing Commission, 2004; Federal Sentencing Guidelines, 2004).

\section{Concluding Comment}

The approach described above addresses one issue discussed in this article: it provides a way for a risk analytic approach to be inserted into an ethical assessment exercise and to extend the scope of analysis by focusing on what might provisionally be called ethical risks. Consideration of measures that might be taken to treat those risks also becomes part of the analysis.

Less obviously, the Veritas Institute's methodology provides a basis for articulating the values that should inform an organization's risk management 
efforts. As stated above, those values, the arraying of those values and the relative importance of those values will differ from organization to organization. Nevertheless, the articulation of values in light of the Ethical Organizational Culture concept should provide direction to an ISO 31000-inspired effort to structure risk management in alignment with the organization's espoused values.

There are numerous other areas of inquiry when considering both the challenge of managing ethics-based risks and reflecting organizational values in risk management policy and practice - and indeed the authors encourage additional investigation as there is not a lot of research currently available on this general subject area. Of particular interest would be:

- There is a potentially lively discussion between directors of risk or chief risk officers and corporate ethics officers. Their responsibilities have many common features: multi-disciplinary, organization-spanning, subject matter that is embedded in virtually all organizational activities and so on. Can ethics and risk management efforts coordinate or leverage off one another?

- How exactly does an assessment of vulnerability to ethical risks connect to more tangible risk exposures? For example, how can an assessment of the ethical dimension of financial risks be fitted into the quantitative assessment of the financial risk itself? The recent/current financial crisis clearly shows that financial institutions did not fall victim to bad mathematics alone, but a combination of technical problems and human behavior. It would be interesting to assess how well financial and operational risk management efforts have been integrated in financial institutions post-2008.

- While there is a sense that 'ethical risks' may be a convenient categorization of certain risks, there really needs to be a better exploration of what this exactly means. Work to date has been largely speculative on this subject.

- There does need to be a clearer examination of ISO's implied values as conceivably there are potential conflicts between those values and an adopting organization's values. Indeed, there are at least two dimensions to this: first, differences between espoused organizational values and ISO implied values, and second, differences between espoused and practiced organizational values and the relationship between that gap and ISO implied values. For example, it has been recently observed that transparency, which has seeming importance as a goal of ISO 31000, may run afoul of top manager concerns about 'too much transparency'.

\section{References}

Andersen, T.J. and Schrøder, P.W. (2010) Strategic Risk Management Practice: How to Deal Effectively with Major Corporate Exposures. Cambridge, UK: Cambridge University Press. 
Ardichvili, A. and Jondle, D. (2009) Ethical business cultures: A literature review and implications for HRD. Human Resource Development Review 8(2): 223-244.

Ardichvili, A., Mitchell, J. and Jondle, D. (2009) Characteristics of ethical business cultures. Journal of Business Ethics 85(4): 445-451.

Beck, U. (1992) Risk Society: Towards a New Modernity. London: Sage Publications.

Boatright, J.R. (2011) The ethics of risk management: A post-crisis perspective. White Paper, Loyola University, Chicago.

Brinkmann, B. and Johnson, E. (2011) The Catholic Identity Matrix - Seeing Mission in All We Do. Ascension Health, internal memorandum.

Brown, M. and Trevino, L. (2006) Ethical leadership: A review and future directions. Leadership Quarterly 17(6): 595-616.

Carroll, A. and Buchholtz, A. (2009) Business \& Society: Ethics and Stakeholder Management. Mason, OH: South-Western Cengage Learning.

Cohen, D. (1993) Creating and maintaining ethical work climates: Anomie in the workplace and implications for managing change. Business Ethics Quarterly 3(4): 343-358.

Collins, J. and Porras, J. (1994) Built to Last: Successful Habits of Visionary Companies. New York: Harper Business.

Dion, M. (1996) Organizational culture as matrix of corporate ethics. International Journal of Organizational Analysis 4(4): 329-351.

Freeman, R.E. (1994) The politics of stakeholder theory: Some future directions. Business Ethics Quarterly 4(4): 409-421.

Freeman, R.E., Gilbert, D.R. and Hartman, E. (1988) Values and the foundation of strategic management. Journal of Business Ethics 7(11): 821-834.

George, B. (2003) Authentic Leadership: Rediscovering the Secrets to Creating Lasting Value. San Francisco, CA: Jossey-Bass.

Goodpaster, K.E. (1997) Moral projection, principle of. In: P.H. Werhane and R.E. Freeman (eds.) Blackwell Encyclopedic Dictionary of Business Ethics. Malden, MA: Blackwell Publishing, p. 432.

Goodpaster, K.E. (2007) Conscience and Corporate Culture. Malden, MA: Blackwell Publishing.

Handy, C. (2002) What's a business for? Harvard Business Review 80(12): 49-55.

International Organization for Standardization (ISO). (2009) ISO: 31000, Risk Management - Principles and Guidelines, Final Draft. Geneva, Switzerland: International Organization for Standardization.

Jondle, D., Ardichvili, A. and Mitchell, J. (forthcoming) Modeling ethical business culture: Development of the Ethical Business Culture Survey and its use to validate the CEBC model of ethical business culture. Journal of Business Ethics, accepted.

Lencioni, P (2002) Making your values mean something. Harvard Business Review 80(7): 113-117.

Maines, T.D. (2011) Self-assessment and improvement process for organizations. In: L. Bouckaert and L. Zsolnai (eds.) The Palgrave Handbook of Spirituality and Business. New York: Palgrave Macmillan, pp. 359-368.

Schein, E.H. (2004) Organizational Culture and Leadership. San Francisco: Jossey-Bass.

Schrøder, P.W. (2006) Impediments to effective risk management. In: T.J. Andersen (ed.) Perspectives on Strategic Risk Management. Copenhagen, Denmark: Copenhagen Business School Press, pp. 65-87.

Smith, D. and Fischbacher, M. (2009) The changing nature of risk and risk management: The challenge of borders, uncertainty and resilience. Risk Management 11(1): 1-12. 
Trevino, L. and Nelson, K. (2004) Managing Business Ethics: Straight Talk about How to Do It Right. New York: Wiley.

United States Sentencing Commission (2012) Guideline Manual, 3E11, Ch. 8: 488-531. Williams, C.A., Smith, M.S. and Young, P.C. (1998) Risk Management and Insurance. New York: McGraw-Hill Book Company.

World Economic Forum. (2011) Global Risks 2011, 6th edn. Davos: The World Economic Forum's Risk Response Network.

Young, P.C. (2004) Ethics and risk management: Building a framework. Risk Management 6(3): 23-34.

Young, P.C. (2010) Risk management. In: J. Boatright (ed.) Finance Ethics: Critical Issues in Financial Theory and Practice. New York: Wiley-Blackwell Publishers, pp. 495-509. 